Working Paper 2010:3

Department of Economics

\title{
Marginal Deadweight Loss when the Income Tax is Nonlinear
}

Sören Blomquist and Laurent Simula 
Department of Economics

Uppsala University

P.O. Box 513

SE-751 20 Uppsala

Sweden

Fax: $+{ }_{4} 6184711478$
Working paper 2010:3

February 2010

ISSN 1653-6975

\section{Marginal Deadweight Loss When THE INCOME TAX Is NonlineAR}

SÖRen Blomquist and Laurent Simula

Papers in the Working Paper Series are published on internet in PDF formats.

Download from http://www.nek.uu.se or from S-WoPEC http://swopec.hhs.se/uunewp/ 


\title{
Marginal Deadweight Loss when the Income Tax is Nonlinear
}

\author{
Sören Blomquist and Laurent Simula \\ Uppsala University and Uppsala Center for Fiscal Studies*
}

February 1, 2010

\begin{abstract}
Almost all theoretical work on how to calculate the marginal deadweight loss has been done for linear taxes and for variations in linear budget constraints. This is quite surprising since most income tax systems are nonlinear, generating nonlinear budget constraints. Instead of developing the proper procedure to calculate the marginal deadweight loss for variations in nonlinear income taxes a common procedure has been to linearize the nonlinear budget constraint and apply methods that are correct for variations in a linear income tax. Such a procedure leads to incorrect results. The main purpose of this paper is to show how to correctly calculate the marginal deadweight loss when the income tax is nonlinear. A second purpose is to evaluate the bias in results that obtains when the traditional linearization procedure is used. We perform calculations based on the 2006 US tax system and find that the relative deadweight loss caused by increasing existing tax rates is large but less than half of Feldstein's (1999) estimates for the 1994 tax system.
\end{abstract}

Keywords: Deadweight Loss, Taxable Income, Nonlinear Budget Constraint JEL classification: H21, H24, H31, D61

${ }^{*}$ Uppsala University, Department of Economics, P.O. Box 513, SE-75120 Uppsala, Sweden. E-mail: soren.blomquist@nek.uu.se and laurent.simula@nek.uu.se

${ }^{\dagger}$ We are grateful to Etienne Lehmann, Luca Micheletto and Håkan Selin for very helpful comments and suggestions. 


\section{Introduction}

The study of the deadweight loss of taxation has a long tradition in economics going back as far as Dupuit (1844). Modern type of empirical work on the deadweight loss of taxation is heavily influenced by the important work of Harberger in the fifties and sixties (see for example Harberger $(1962,1964)$ ). A second generation of empirical work was inspired by Feldstein $(1995,1999)$. Feldstein argued that previous studies had neglected many important margins that are distorted by taxes. By estimating how total taxable income reacts to changes in the marginal tax, one would be able to capture distortions of all relevant margins. Feldstein's own estimates indicated large welfare losses whereas many later studies arrived at estimates of the welfare loss that were larger than those obtained in pre-Feldstein studies, but considerably lower than the estimates obtained by Feldstein. An important ingredient in modern studies of the deadweight loss of taxes is the estimation of a (Hicksian) taxable income supply function (Gruber and Saez, 2002; Kopczuk, 2005; Saez, 2010; Saez, Slemrod, and Giertz, 2009). These taxable income functions show how taxable income varies as the slope of a linear budget constraint of individuals is changed at the margin.

Almost all theoretical work on how to calculate the marginal deadweight loss has been done for linear taxes and hence for variations in linear budget constraints. This is quite surprising since most income tax systems are nonlinear, generating nonlinear budget constraints. Instead of developing the proper procedure to calculate the marginal deadweight loss for variations in nonlinear income taxes, one has linearized the nonlinear budget constraint and applied the procedure that is correct for variations in a linear income tax. As we will show, this leads to incorrect results. The main purpose of our article is to show how to correctly calculate the marginal deadweight loss when the income tax is nonlinear. A second purpose is to evaluate the bias in results that obtains when the traditional linearization procedure is used. For tax systems where the marginal income tax increases with the taxable income, this linearization procedure may often lead to an overestimate of the marginal deadweight loss.

Actual tax systems are usually piecewise linear and, in the end, we describe how to calculate the marginal deadweight loss for such tax systems. However, in order to get simple and clean results, we start our analysis by considering smooth budget constraints. We then describe how results are modified when the budget constraints are piecewise linear. It should be noted that the average, or aggregate, behavior for a population does not depend on whether the tax system and budget constraints are kinked or smooth. It is the general shape of the tax system and budget constraints that determine the 
average behavior. ${ }^{1}$ To simplify the analysis, we consider tax systems that generate convex budget sets. ${ }^{2}$ Historically, much focus has been on how the income tax distorts labor supply. Since the more recent literature has the focus on taxable income, we state our results in terms of this concept. Of course, it is easy to modify our results to some other application.

The layout of the rest of this article is as follows. Section 2 gives the results for a smooth budget constraint. Section 3 derives the results for a piecewise linear budget constraint. Section 4 presents a numerical computation for the US tax system and Section 5 concludes.

\section{Marginal Deadweight Loss when the Budget Constraint is Smooth}

A linear income tax can be varied in two ways. One can change the intercept, which leads to a pure income effect, or change the proportional tax rate, which leads to a substitution and an income effect. For a nonlinear income tax, there are many more possible ways to vary the tax. Break points can be changed, the intercept can be changed and the slope can also be changed. Moreover, the slope can be changed in different ways. We do not cover all these different possibilities to vary a nonlinear tax. We focus on a particular kind of change in the slope, namely a change in the slope such that the marginal tax changes with the same number of percentage points at all income levels. Therefore, we model the tax in the following way. Let $A$ denote taxable income and the tax on $A$ be given by $T(A)=g(A)+t A$, with $g^{\prime}(A)>0, g^{\prime \prime}(A)>0$ and $t \geqq 0$. We can think of $g(A)$ as a nonlinear federal tax. There are several alternative interpretations of $t A$. It could be a payroll tax, a value added tax or a proportional state income tax. Within the Scandinavian framework, it could be interpreted as the local community tax. What we study is the marginal deadweight loss of an increase in $t$. A change in $t$ implies that the marginal tax is increased by the same percentage point at all income levels.

There are two good reasons why we have chosen to parameterize the tax system in the way described above. When we vary the slope of a linear budget constraint, the

\footnotetext{
${ }^{1}$ This should be qualified. A smooth tax schedule is a good approximation of a piecewise linear tax schedule provided the distribution of the kink points is regular enough.

${ }^{2}$ This assumption is just for simplicity. The general insights of the article applies also to the case with a concave budget set. If the curvature of the indifference curves is larger than the curvature of the budget constraint so that an interior unique solution of the individual's utility maximization problem obtains, most of the formulas below apply. The analysis becomes more complex if the budget constraint is concave and more curved than the indifference curves. One then has to take the possibility of multiple solutions and/or corner solutions into account.
} 
intercept will not change. It is of value to have a parameterization of the nonlinear tax that has a similar property. When we in the next section study the marginal deadweight loss for a piecewise linear budget constraint, we will see that, for the parameterization used, a change in $t$ will not change the virtual incomes but only the slope, thereby giving a clean experiment similar to a change in the slope of a linear budget constraint. ${ }^{3} \mathrm{~A}$ second reason is, of course, that real tax systems are of a form as the one described by $g(A)+t A$.

Consider the utility maximization problem:

$$
\max _{A, C} U(C, A, v) \text { s.t. } C \leqq A-g(A)-t A+B
$$

where $C$ is consumption, $v$ an individual specific preference parameter and $B$ lump-sum income. We assume that the utility function $U(C, A, v)$ has the usual properties and that the tax system defines a convex budget set. We denote the solution to problem (P1) as $A(t, B, v), C(t, B, v)$. The form of these two functions depends on the functional forms of $U$ and $g$. Sticking $A(t, B, v), C(t, B, v)$ back into the utility function, we obtain the indirect utility $\bar{u}(v):=U(C(t, B, v), A(t, B, v), v)$. For each individual, the latter is the maximum utility level obtained under the given tax system. Because individuals have different $v$ 's, they chose different taxable incomes and have different $\bar{u}(v)$. To simplify the notations, we henceforth suppress the $v$ in $\bar{u}(v)$. However, it should be kept in mind that the $\bar{u}$ given in expressions below vary between individuals.

We now study the marginal deadweight loss of a small increase in $t$. We first derive the correct expression and then describe how it usually is calculated. For this purpose, we define the expenditure function as:

$$
E(t, v, \bar{u})=\min _{A, C}\{C-A+g(A)+t A-B\} \text { s.t. } U(C, A, v) \geqq \bar{u}
$$

This problem also defines the compensated supply and demand functions, $A^{h}(t, v, \bar{u})$ and $C^{h}(t, v, \bar{u})$ respectively, where the superscript $h$ denotes that it is Hicksian functions. It is important to note that these functions depend on the functional form of $U(C, A, v)$ and on the functional form of $g(A)$. In almost all empirical and theoretical analyses, we work with demand and supply functions generated by linear budget constraints. In contrast, the functions defined by (P1) and (P2) are generated by a nonlinear budget constraint.

\footnotetext{
${ }^{3}$ This nice feature of the parameterization used was pointed out to us by Håkan Selin.
} 
Let us define the compensated revenue function as:

$$
R\left(A^{h}(t, v, \bar{u})\right)=g\left(A^{h}(t, v, \bar{u})\right)+t A^{h}(t, v, \bar{u})
$$

and the marginal deadweight loss as:

$$
\begin{aligned}
D W & =\frac{d E(t, v, \bar{u})}{d t}-\frac{d R\left(A^{h}(t, v, \bar{u})\right)}{d t} \\
& =A^{h}-g^{\prime}\left(A^{h}\right) \frac{d A^{h}}{d t}-A^{h}-t \frac{d A^{h}}{d t}=-\left(g^{\prime}\left(A^{h}\right)+t\right) \frac{d A^{h}}{d t},
\end{aligned}
$$

where we used the envelope theorem to obtain $d E(t, v, \bar{u}) / d t=A^{h}$. Expression $(2)$ is the correct expression for the marginal deadweight loss.

We next describe a commonly used procedure that, in general, overestimates the marginal deadweight loss. Let us consider particular values $v^{*}, t^{*}$ and $B^{*}$ and the solution to (P1), $A^{*}=A\left(t^{*}, v^{*}, B^{*}\right), C^{*}=C\left(t^{*}, v^{*}, B^{*}\right)$. We can linearize the budget constraint around this point with local prices defined by $p_{c}=1$ and $p_{A}=g^{\prime}\left(A^{*}\right)+t^{*}$ to obtain the linear budget constraint $C=A-p_{A} A+M$, where $M$ is defined as $M=C^{*}-A^{*}+p_{A} A^{*}$. Consider the problem:

$$
\max _{A, C} U\left(C, A, v^{*}\right) \text { s.t. } C \leqq A-p_{A} A+M \text {. }
$$

We call $A_{L}\left(p_{A}, v^{*}, M\right), C_{L}\left(p_{A}, v^{*}, M\right)$ the solution to this problem. Here, we use the subscript $L$ to show that these are functions generated by a linear budget constraint.

We define the expenditure function corresponding to this linear budget constraint as

$$
E_{L}(t, v, \bar{u})=\min _{A, C}\left\{C-A+p_{A} A-M\right\} \text { s.t. } U(C, A, v) \geqq \bar{u}
$$

and denote its solution by $A_{L}^{h}(t, v, \bar{u}), C_{L}^{h}(t, v, \bar{u})$, where the subscript $L$ indicates that it is the solution to a problem where the objective function is linear and the superscript $h$ that this is Hicksian demand-supply functions. Let us define the compensated revenue function as: $R\left(A_{L}^{h}(t, v, \bar{u})\right)=g\left(A_{L}^{h}(t, v, \bar{u})\right)+t A^{h}(t, v, \bar{u})$. We define the marginal deadweight loss as:

$$
\begin{aligned}
D W_{L} & =\frac{d E_{L}(t, v, \bar{u})}{d t}-\frac{d R_{L}\left(A_{L}^{h}(t, v, \bar{u})\right)}{d t} \\
& =A_{L}^{h}-g^{\prime}\left(A_{L}^{h}\right) \frac{d A_{L}^{h}}{d t}-A_{L}^{h}-t \frac{d A_{L}^{h}}{d t}=-\left(g^{\prime}\left(A_{L}^{h}\right)+t\right) \frac{d A_{L}^{h}}{d t} .
\end{aligned}
$$




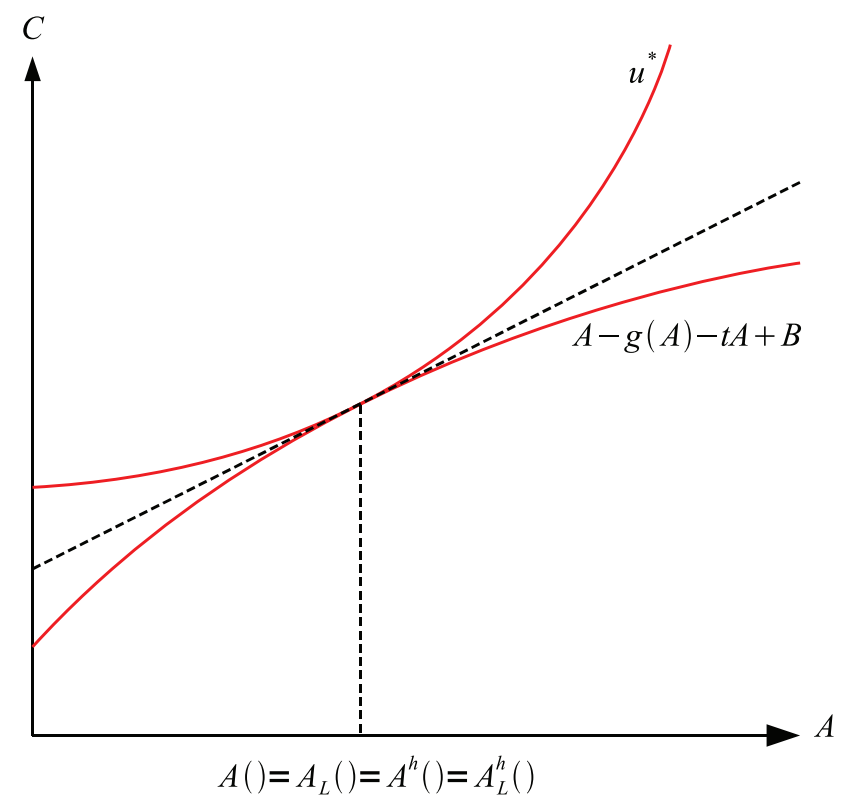

Figure 1: Nonlinear and Linearized Programmes

Figure 1 illustrates the four optimization problems that we have studied. The optimization problem (P1) maximizes utility given the curved budget constraint in the figure. Let us consider particular values for the proportional tax and lump-sum income: $t^{*}$ and $B^{*}$. Suppressing the dependence on $v$, we denote the solution by $A^{*}=A\left(t^{*}, B^{*}\right), C^{*}=$ $C\left(t^{*}, B^{*}\right)$. This defines the utility level $u^{*}=U\left(C^{*}, A^{*}\right)$. Optimization problem (P2) minimizes expenditures to reach the utility level $u^{*}$ for the given nonlinear tax system. By construction, the solution to this problem is also $A^{*}, C^{*}$. Linearizing around $\left(A^{*}, C^{*}\right)$, so that the linear budget constraint is tangent to the indifference curve at $\left(A^{*}, C^{*}\right)$, we have two other optimization problems. Problem (P3) maximizes utility subject to the linear budget constraint going through $\left(A^{*}, C^{*}\right)$ and having the same slope as the indifference curve through $\left(A^{*}, C^{*}\right)$. Problem (P4) is to minimize expenditures given the utility level $u^{*}$ and the general shape of the budget constraint given by the linear budget constraint. By construction, the four optimization problems have the same solution. For any $t$ and $B$, we have the identities

$$
\begin{aligned}
& A(t, B) \equiv A^{h}(U(C(t, B), A(t, B))) \\
& \equiv A_{L}\left(p_{A}(C(t, B), A(t, B)), M(C(t, B), A(t, B))\right) \equiv A_{L}^{h}(U(C(t, B), A(t, B))) .
\end{aligned}
$$

Expressions (2) and (3) look quite similar. By construction, it is true that $A_{L}^{h}=A^{h}$, 
implying that $g^{\prime}\left(A_{L}^{h}\right)+t=g^{\prime}\left(A^{h}\right)+t$. However, $d A^{h} / d t$ and $d A_{L}^{h} / d t$ differ. To show this, we start with a simple example, which we then generalize.

\subsection{Simple Example}

To simplify notation, we in this example suppress the preference parameter $v$. Assume the utility function takes the quasilinear form $U=C-\alpha A-\beta A^{2}$. This implies that the income effect for the supply of $A$ is zero, so that the Marshallian and Hicksian supply functions are the same. We assume that the tax is given by $T(A)=t A+p A+\pi A^{2}$, where we can interpret $t A$ as a state tax and $p_{A} A+\pi A^{2}$ as the federal tax. This yields a budget constraint $C=A-(p+t) A-\pi A^{2}+B$, where $B$ is lump-sum income. Substituting the budget constraint into the utility function, we obtain $U=A-(p+t) A-\pi A^{2}+B-$ $\alpha A-\beta A^{2}$. Maximizing with respect to $A$, we get $d U / d A=1-(p+t)-2 \pi A-\alpha-2 \beta A$. We see that a necessary condition for a non-negative $A$ is $1-(p+t)-\alpha \geqq 0$. We find that $d^{2} U / d A^{2}=-2(\pi+\beta)<0$ for $\pi+\beta>0$. Setting $d U / d A=0$ and solving for $A$, we obtain

$$
A=\frac{1-(p+t)-\alpha}{2(\pi+\beta)} .
$$

Since we have the quasi-linear form, this is also the Hicksian supply. We immediately have

$$
\frac{d A^{h}}{d t}=-\frac{1}{2(\pi+\beta)} .
$$

From (6), we see that the size of the substitution effect depends on the curvatures of the indifference curve and the budget constraint. We note that it is immaterial whether the curvature emanates from the indifference curve or from the budget constraint. What matters is the curvature of the indifference curve in relation to the budget constraint. The larger the total curvature, given by $2(\pi+\beta)$ in our example, the smaller is the deadweight loss.

Suppose that we have particular values for the parameters of the problem and denote the solution $\left\{C^{*}, A^{*}\right\}$. We can linearize the budget constraint around this point and get the budget constraint $C=A-\left[(p+t)+2 \pi A^{*}\right] A+M$, where $M=$ $C^{*}-\left[1-(p+t)-2 \pi A^{*}\right] A^{*}$.

Consider the problem:

$$
\max _{C, A}\left\{C-\alpha A-\beta A^{2}\right\} \text { s.t. } C \leqq A-\left[(p+t)+2 \pi A^{*}\right] A+M
$$

Substituting the binding budget constraint into the utility function, we want to maximise 
$A-\left[(p+t)+2 \pi A^{*}\right] A+M-\alpha A-\beta A^{2}$. Denoting this expression by $\widetilde{U}$, we obtain $d \widetilde{U} / d A=1-(p+t)-2 \pi A^{*}-\alpha-2 \beta A$ and $d^{2} \widetilde{U} / d A^{2}=-2 \beta$. The second-order condition is satisfied for $\beta>0$. Setting $d \widetilde{U} / d A=0$ and solving for $A$, we get $A_{L}^{h}=$ $\left(1-(p+t)-2 \pi A^{*}-\alpha\right) /(2 \beta)$ and

$$
\frac{d A_{L}^{h}}{d t}=-\frac{1}{2 \beta}
$$

Suppose $\pi=\beta=0.1$. We then have that $d A^{h} / d t=-2.5$ while using the supply function generated by the linearized budget constraint gives $d A_{L}^{h} / d t=-5$. This means that the linearization procedure overestimates the deadweight loss with a factor 2 .

In Figure 2, we illustrate the deadweight loss of a discrete change in $t$, from $t=0$ to $t=0.3$, for parameter values of $\alpha=\beta=0.1, p=0.2, \pi=0.05$ and $B=1$. In the left panel, we show the correct calculation of the deadweight loss using a variation in the nonlinear budget constraint. The bundle chosen prior to the tax change is $A$, at the tangency point between the budget constraint and the highest feasible indifference curve. The increase in $t$ shifts the nonlinear budget constraint in such a way that $A^{\prime}$ is now chosen instead of $A$. The deadweight loss corresponds to the difference between the equivalent variation and the variation in tax revenue. It is thus shown by the thick vertical line below $A^{\prime}$. In the right panel, we show the standard procedure which employs a variation in the linearized budget constraint. The nonlinear budget constraint through $A$ is linearized around this point. The increase in $t$ induces a rotation of the linearized budget constraint around the intercept. The bundle $A_{L}$ is now chosen instead of $A$. We see that the deadweight loss, shown by the thick vertical line below $A_{L}$, is much larger than when the correct procedure is used.

\subsection{General Utility Function}

We can easily generalize the above. Let us consider the general utility function $U(C, A, v)$. The Hicksian supply function for taxable income is defined by problem (P2). We will reformulate this problem. The constraint $U(C, A, v) \geqq \bar{u}$ is binding at the optimum and can thus be rewritten as $C=f(A, v, \bar{u})$, where the function $f$ is defined by $U(f(A, v, \bar{u}), A, v)=\bar{u}$. Substituting the constraint $C=f(A, v, \bar{u})$ into the objective function, we obtain the minimization problem $\min _{A} f(A, v, \bar{u})-A+t A+g(A)-B$. Let us for convenience use the notation $f^{\prime}()$ to denote $\partial f / \partial A$. The first order condition $f^{\prime}(A, v, \bar{u})-1+t+g^{\prime}(A)=0$ defines the Hicksian supply function $A^{h}(t, v, \bar{u})$. 

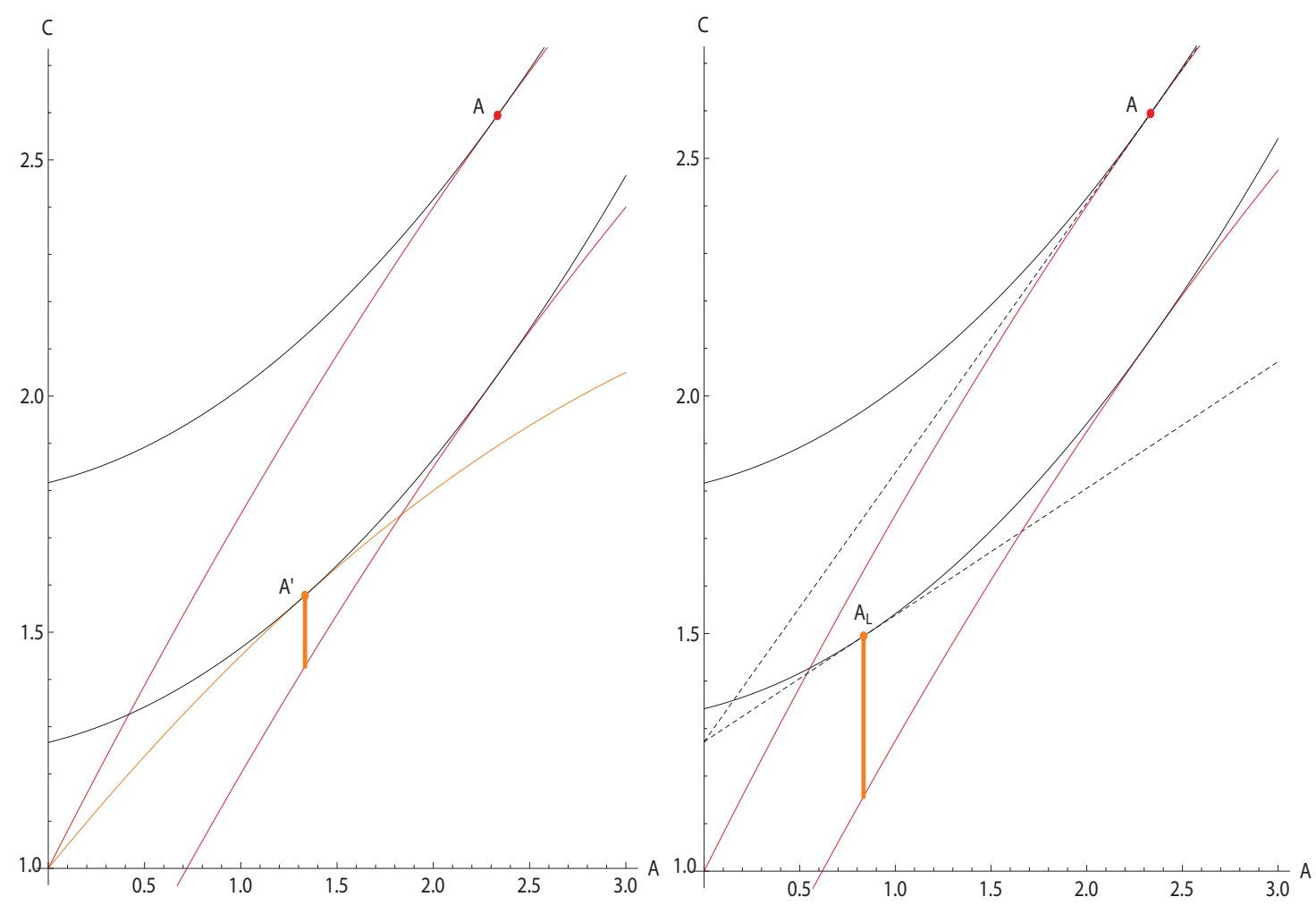

Figure 2: Deadweight loss when the budget constraint is nonlinear (left panel) and linearized (right panel)

Differentiating it implicitly yields:

$$
\frac{d A^{h}}{d t}=-\frac{1}{g^{\prime \prime}+f^{\prime \prime}}
$$

In the analysis above $f^{\prime}(A, v, \bar{u})$ is the slope of the indifference curve and $f^{\prime \prime}(A, v, \bar{u})$ shows how the slope of the indifference curve changes as $A$ is increased along the indifference curve. Hence, it gives the curvature of the indifference curve. For the special case of a quasilinear utility function, with zero income effects for the taxable income function, $\bar{u}$ would not be an argument in the $f()$ function.

We have seen that the curvature of the budget constraint is as important for the size of the marginal deadweight loss as is the curvature of the indifference curve. What matters is the curvature of the indifference curve in relation to the budget constraint.

From (9), we see that $d A^{h} / d t$ reduces to $d A^{h} / d t=-1 / f^{\prime \prime}$ if the budget constraint is linear and $g^{\prime \prime}=0$. Hence, if we linearized and used a linear objective function, we would 
obtain

$$
\frac{d A_{L}^{h}}{d t}=-\frac{1}{f^{\prime \prime}}
$$

In empirical studies of the taxable income function, it is the taxable income function $A_{L}^{h}(t, v, \bar{u})$, valid for a linear budget constraint, that is estimated and reported. However, if we know $d A_{L}^{h} / d t$ as well as the tax function $T(A)=g(A)+t A$, it is easy to calculate the comparative statics for the taxable income function $A^{h}(t, v, \bar{u})$. This is because the comparative statics for the two functions are related according to the formula:

$$
\frac{d A^{h}}{d t}=\frac{d A_{L}^{h} / d t}{1-g^{\prime \prime}(A)\left(d A_{L}^{h} / d t\right)}
$$

\subsection{Marginal Deadweight Loss for the Population}

From a welfare point of view, there is no obvious way how one should aggregate the marginal deadweight loss for different individuals. However, it is fairly common to calculate the average or total marginal deadweight loss. Without loss of generality, we choose to normalize the size of the population to 1 in the rest of the paper. Hence, the average and total measures are the same and we will speak of "aggregate marginal deadweight loss" to refer to the marginal deadweight loss for the entire population.

The latter can be computed in the following way. Suppose that the distribution $v$ in the population is described by the continuous pdf $\phi(v)$ with support over $(\underline{v}, \bar{v})$. Using (2), the aggregate marginal deadweight loss is given by

$$
-\int_{\underline{v}}^{\bar{v}}\left(g^{\prime}\left(A^{h}\right)+t\right) \frac{d A^{h}}{d t} \phi(v) d v
$$

By (3), we could give a similar expression for the marginal deadweight loss calculated with the function $A_{L}^{h}$. Since for any $v$, we have that $\left|d A^{h} / d t\right|<\left|d A_{L}^{h} / d t\right|$, it is clear that the aggregate marginal deadweight loss calculated with the function $A_{L}^{h}$ gives a higher value than if calculated using $A^{h}$. If some other weighting were used, we would get a similar result. For example, we might weigh by incomes as is sometimes done in the literature. That would of course change the numerical results but the qualitative results would still hold.

We will not give a numerical example here but instead do this for the piecewise linear case. 


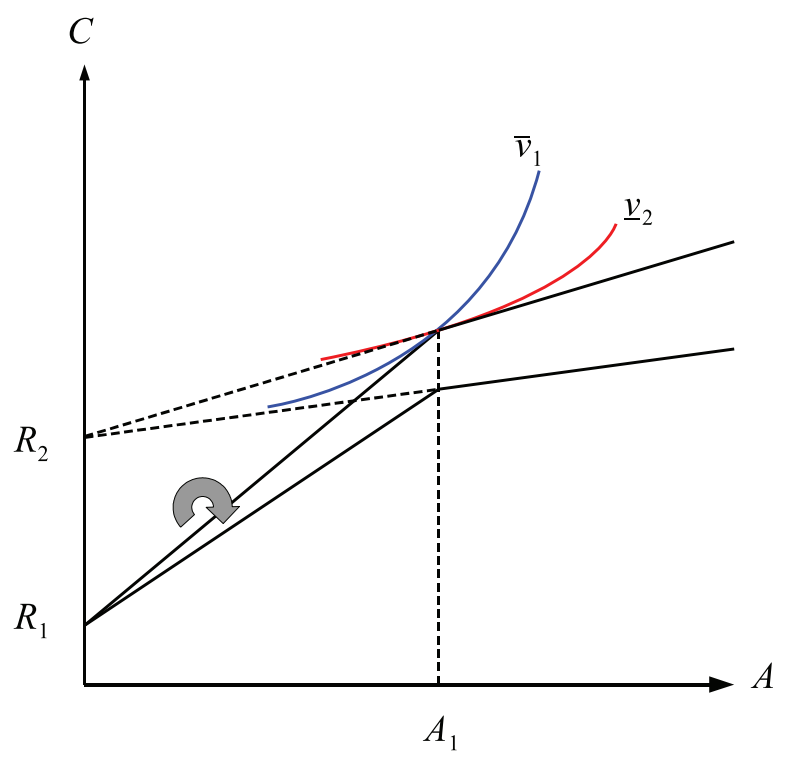

Figure 3: Piecewise Linear Budget Constraints

\section{Marginal Deadweight Loss when the Budget Constraint is Piecewise Linear}

We now consider the marginal deadweight loss when the tax system is piecewise linear. The tax system that we consider is of the same form as above, but the federal tax is piecewise linear. To illustrate the mechanisms at work, it is sufficient to consider a tax system generating a budget constraint with two linear segments and one kink point. The results easily generalize to a tax system with many kinks. In a numerical example below, we consider a tax system with three linear segments and two kinks.

Let the federal tax system be characterized by the marginal tax rate $\tau_{1}$ for taxable income up to the break point $A_{1}$ and the marginal tax $\tau_{2}$ for incomes above the break point. Let there also be a state income tax of $t$. The budget constraint generated by this tax system is shown in Figure 3. The intercept for the first segment, $R_{1}$, is lump-sum income. The slope on the first segment is given by $\theta_{1}=1-\tau_{1}-t$ and for the second segment by $\theta_{2}=1-\tau_{2}-t$. The virtual income for the second linear segment is given by $R_{2}=R_{1}+\left(\theta_{1}-\theta_{2}\right) A_{1}=R_{1}+\left(\tau_{2}-\tau_{1}\right) A_{1}$. Hence, the virtual income $R_{2}$ does not depend on $t$ and does not change if $t$ is varied.

To make the problem interesting, we need some individuals locating in the interior of the segments and some at the kink point. Hence, we now re-introduce the hetero- 
geneity parameter $v$ explicitly and write the utility function $U(C, A, v)$, where $v$ is a preference parameter with pdf $\phi(v)$ over $(\underline{v}, \bar{v})$. If we had a pure labor supply model, it would be natural to write the utility function as $U(C, A / v)$ and interpret $v$ as the wage rate. However, since in the taxable income literature, it is assumed that there are other margins than hours of work, we prefer to write it in the more general form $U(C, A, v)$. For one interval of $v$, we would have solutions on the first segment; for another interval, at the kink point and, for a third interval, on the second segment.

A first step is to find out how the budget constraint changes as the tax parameter $t$ increases. We know that $R_{1}$ and $R_{2}$ do not change. The slopes of the first and second segments decrease. The kink point is still at $A_{1}$. However, its $C$-coordinate decreases by $d t \times A_{1}$, the amount of the extra tax paid. For a person located at the kink point before and after the change in $t$, we have $d A^{h} / d t=0$. Therefore, there is no marginal deadweight loss from the increase in $t$ for this person. The increase in taxes paid by a person located at the kink is just like a lump-sum tax. For a person with a tangency on one of the linear segments, the variation in the budget constraint is just like a variation in a linear budget constraint. For such a person, one can therefore apply the taxable income function that is generated by a linear budget constraint and the marginal deadweight loss for an individual with parameter $v$ would be given by

$$
-\left(\tau_{i}+t\right) \frac{d A_{L}^{h}\left(\tau_{i}+t, v, \bar{u}\right)}{d t}
$$

with $i=1,2$, where we should remember that $\bar{u}$ is a function of $v$.

If we want to find the aggregate marginal deadweight loss, we can integrate over $v$. For simplicity, we assume that $v$ enters the utility function in such a way that $A_{L}^{h}$ is strictly increasing in $v$. We also assume that $0<A_{L}^{h}\left(\tau_{1}+t, \underline{v}, \bar{u}\right)<A_{1}<$ $A_{L}^{h}\left(\tau_{2}+t, \bar{v}, \bar{u}\right)$ : no one chooses the zero solution and there are individuals choosing a bundle on the first segment, some others at the kink and some others on the second segment. Let $\bar{v}_{1}$ be defined by $A_{L}^{h}\left(\tau_{1}+t, \bar{v}_{1}, \bar{u}\right)=A_{1}$ and $\underline{v}_{2}$ by $A_{L}^{h}\left(\tau_{2}+t, \underline{v}_{2}, \bar{u}\right)=A_{1}$ as shown in Figure 3. Define the subsets $S_{1}=\left(\underline{v}, \bar{v}_{1}\right)$ and $S_{2}=\left(\underline{v}_{2}, \bar{v}\right)$. Likewise define the set $K_{1}=\left(\bar{v}_{1}, \underline{v}_{2}\right)$. Then individuals with $v \in S_{1}$ will have a solution on the first segment, individuals with $v \in S_{2}$ on the second segment and persons with $v \in K_{1}$ a solution at the kink point.

The aggregate (non-marginal) deadweight loss is an expression that can be written as

$$
\int_{S_{1}} \delta_{1}(t, v) \phi(v) d v+\int_{K_{1}} \delta_{2}(t, v) \phi(v) d v+\int_{S_{2}} \delta_{3}(t, v) \phi(v) d v
$$


where $\delta$ generically represents the (non-marginal) deadweight loss for person $v$. The aggregate marginal deadweight loss is the derivative of this expression with respect to $t$, which by Leibnitz's rule is equal to

$$
\begin{aligned}
& \int_{S_{1}} \delta_{1 t}^{\prime}(t, v) \phi(v) d v+\bar{v}_{1}^{\prime}(t) \delta_{1}\left(t, \bar{v}_{1}(t)\right) \phi\left(\bar{v}_{1}(t)\right) \\
& +\int_{K_{1}} \delta_{2 t}^{\prime}(t, v) \phi(v) d v+\underline{v}_{2}^{\prime}(t) \delta_{2}\left(t, \underline{v}_{2}(t)\right) \phi\left(\underline{v}_{2}(t)\right)-\bar{v}_{1}^{\prime}(t) \delta_{2}\left(t, \bar{v}_{1}(t)\right) \phi\left(\bar{v}_{1}(t)\right) \\
& +\int_{S_{2}} \delta_{3 t}^{\prime}(t, v) \phi(v) d v-\underline{v}_{2}^{\prime}(t) \delta_{3}\left(t, \underline{v}_{2}(t)\right) \phi\left(\underline{v}_{2}(t)\right) .
\end{aligned}
$$

To compute the (non-marginal) deadweight loss for person $\bar{v}_{1}$ or $\underline{v}_{2}$, we need to consider his taxable income and his highest feasible indifference curve. So, it is not the slope of the budget constraint that matters here. The slope of the budget constraint matters when evaluating his marginal deadweight loss. We thus have $\delta_{1}\left(t, \bar{v}_{1}(t)\right)=\delta_{2}\left(t, \bar{v}_{1}(t)\right)$ and $\delta_{2}\left(t, \underline{v}_{2}(t)\right)=\delta_{3}\left(t, \underline{v}_{2}(t)\right)$, which implies that the terms in (15) showing movements in and out of the kink point sum to zero. Consequently, the aggregate marginal deadweight loss is

$$
D W_{T R U E}=-\sum_{i=1}^{2} \int_{S_{i}}\left(\tau_{i}+t\right) \frac{d A_{L}^{h}}{d t} \phi(v) d v+0 \times \int_{K_{1}} \phi(v) d v .
$$

To compute the aggregate marginal deadweight loss, we only integrate along the segments of the budget sets; the contribution from individuals bunched at the kink point is zero.

The difference between the smooth case and the piecewise linear case is that, in the former, the actual marginal deadweight loss is lower than that indicated by the "linear" taxable income function for any $v$ and the corresponding value of $A$. In the piecewise linear case, the difference in the two measures is concentrated to the kink. If there were several kinks, the difference would also be concentrated to the kinks.

\subsection{Comparison of the Deadweight Loss for a Linear versus a Piecewise Linear Budget Constraint}

To get an idea about the numerical difference between the aggregate marginal deadweight loss calculated according to (16) versus using a linearized budget constraint, we consider a numerical example. We consider a functional form for the taxable income function that often has been estimated in the taxable income literature: $A=\theta^{\beta} e^{v}$, where $\theta$ is the slope of a linear budget constraint. Depending on context, the parameter $v$ can be given various interpretations. Here we interpret it as the wage rate (Chetty, 2009). The preference specification implies that we have assumed away income effects and the 
Marshallian and Hicksian supply functions are the same. It also implies that the Hicksian supply function does not depend on $\bar{u}$. Taking $\operatorname{logs}$, it has the form $\ln A=\beta \ln \theta+v$. We readily obtain $d A_{L}^{h} / d t=-\beta A / \theta$, that we combine with (13) to get the marginal deadweight loss as

$$
-(\tau+t) \frac{d A_{L}^{h}}{d t}=(\tau+t) \frac{\beta A}{\theta}=(\tau+t) \beta \theta^{\beta-1} e^{v} .
$$

Assuming that $v$ is uniformly distributed on $[0,1]$, the aggregate marginal deadweight loss for a linear budget constraint with slope $\theta$ is

$$
D W_{L}(\theta)=(\tau+t) \beta \theta^{\beta-1} \int_{0}^{1} e^{v} d v=\beta \theta^{\beta-1}(\tau+t)(e-1) .
$$

Let us next consider the aggregate marginal deadweight loss for a piecewise linear budget constraint with three segments. We denote the break points $A_{1}$ and $A_{2}$. For simplicity, we consider a budget constraint defining a convex budget set. With this form for the taxable income function, we have $S_{1}=\left(0, \ln \left(A_{1} / \theta_{1}^{\beta}\right)\right), S_{2}=\left(\ln \left(A_{1} / \theta_{2}^{\beta}\right), \ln \left(A_{2} / \theta_{2}^{\beta}\right)\right)$ and $S_{3}=\left(\ln \left(A_{2} / \theta_{3}^{\beta}\right), 1\right)$. Likewise we define the bunching sets $K_{1}=\left(\ln \left(A_{1} / \theta_{1}^{\beta}\right), \ln \left(A_{1} / \theta_{2}^{\beta}\right)\right)$ and $K_{2}=\left(\ln \left(A_{2} / \theta_{2}^{\beta}\right), \ln \left(A_{2} / \theta_{3}^{\beta}\right)\right)$. An individual has a solution on segment $i$ if $v \in S_{i}$ and at kink $i$ if $v \in K_{i}$. The integral over $S_{1}$ is

$$
D W_{S_{1}}=\left(\tau_{1}+t\right) \beta \theta_{1}^{\beta-1} \int_{0}^{\ln \left(A_{1} / \theta_{1}^{\beta}\right)} e^{v} d v=\beta\left(\tau_{1}+t\right) \frac{A_{1}-\theta_{1}^{\beta}}{\theta_{1}} .
$$

In a similar way, the integral over $S_{2}$ is

$$
D W_{S_{2}}=\beta\left(\tau_{2}+t\right) \frac{A_{2}-A_{1}}{\theta_{2}}
$$

and over $S_{3}$

$$
D W_{S_{3}}=\beta\left(\tau_{3}+t\right) \frac{e \theta_{3}^{\beta}-A_{2}}{\theta_{3}} .
$$

Following (16), the true marginal deadweight loss is therefore given by $D W_{T R U E}=$ $\sum_{i} D W_{S_{i}}$.

Let us exemplify with some numbers. Empirical studies using the functional form considered in our example have often found a value of $\beta$ around 0.4 (Saez, Slemrod, and Giertz, 2009). Therefore, let $\beta=0.4, A_{1}=1, A_{2}=1.4, \theta_{1}=0.7, \theta_{2}=0.5$ and $\theta_{3}=0.3$ (implying marginal tax rates of $\tau_{1}+t=0.3, \tau_{2}+t=0.5$ and $\tau_{3}+t=0.7$ ). Given these numbers, we find that $D W_{T R U E}=0.398$. There is no obvious way for how 
we should linearize the budget constraint and we therefore consider several alternatives. If we linearize around the first segment, we obtain $D W_{L}\left(\theta_{1}\right)=0.255$. If we linearize around the second segment, we obtain $D W_{L}\left(\theta_{2}\right)=0.521$ and if we linearize around the third $D W_{L}\left(\theta_{3}\right)=0.991$. An unweighted average of $D W_{L}\left(\theta_{1}\right), D W_{L}\left(\theta_{2}\right)$ and $D W_{L}\left(\theta_{3}\right)$ gives 0.589. None of these calculations, building on linearized budget constraints, is a good approximation of the true marginal deadweight loss.

In the example above, we for simplicity assumed a uniform distribution. If we instead had assumed a pdf with more of the density mass in the middle of the support and thinner tails, then, if the interval with higher density were where the kinks are, the marginal deadweight loss $D W_{T R U E}$ would have been lower.

Relatively little research has examined the evidence of bunching at kink points in actual data. Using microdata from US tax returns over the period 1960-97, Saez (2010) finds clear evidence of bunching around the first kink of the Earned Income Tax Credit among self-employed workers and, to a lesser extent, around the threshold of the first tax bracket where tax liability starts. He finds little evidence of bunching at other tax brackets. Other studies have found modest evidence of bunching, for elderly US workers who are both working and receiving social security benefits in Burtless and Moffitt (1984) and Friedberg (2000), above the first eligibility threshold for the UK earned income tax credit in Blundell and Hoynes (2004) or for the Australian Higher Education Contribution Scheme in Chapman and Leigh (2009).

If few persons are found at kink points, we believe there are two possible interpretations of this. One interpretation is that the compensated elasticity is small, i.e., the indifference curves are heavily curved. Another interpretation is that many individuals are planning to be at the kink point, but due to optimization errors are slightly off the goal. The part played by optimization frictions has recently been emphasized by Chetty (2009) who estimates labor supply elasticities. If the first interpretation is correct, it implies that marginal deadweight losses are small and that studies indicating large elasticities are incorrect. If the latter interpretation is correct, it means that the number of individuals that would be at a kink point in the long run, when they have been able to fully adjust to the actual tax schedule, is underestimated in many studies. Whether the low number of individuals actually found at kink points is due to optimization errors or heavily curved indifference curves, the aggregate marginal deadweight loss should be calculated as described above with an assumed (preferably estimated) distribution of the preference term. 


\section{Numerical Application on US Tax System}

This section presents estimates of the average marginal deadweight loss of the US tax system. As in Saez (2010), we consider that individual preferences are described by a quasilinear and isoelastic function of the form

$$
U(C, A, v)=C-\frac{v}{1+1 / \beta}\left(\frac{A}{v}\right)^{1+1 / \beta},
$$

where $v$ can be interpreted as a wage parameter. The quasilinearity assumption implies that there is no income effect on labor supply and that the Marshallian and Hicksian taxable income functions are equal. The isoelastic assumption implies that the elasticity of taxable income is constant, equal to $\beta$. Given the preference specification, a $v$-person facing a linear budget constraint with slope $\theta$ has taxable income $A=v \theta^{\beta}$. As a benchmark, we consider that $\beta=0.4$, but we also provide simulations for $\beta=0.2$ and $\beta=1.04$, the latter value being used by Feldstein (1999).

We take into account the federal income tax, the state income tax, the earned income tax credit, the payroll tax, the state sales tax and the local sales tax. We use the Californian tax schedule to compute the state taxes. California is the state with the largest population and many other states have similar income tax schedules. The payroll tax and the sales taxes are linear. The payroll tax is $15.3 \%$ and the state sales tax in California is $7.25 \%$. Local taxes vary. In our computations, we assume that the local sales tax is $0.5 \%$. Overall, the linear component of the tax system, denoted by $t$ in the previous sections, represents $23.05 \%$ of the taxable income. The earned income tax credit, the federal income tax and state income tax are piecewise linear. Altogether, they give rise to 14 tax brackets. The earned income tax credit creates a nonconvexity of the budget constraint. This nonconvexity for incomes between $\$ 7,550$ and $\$ 30,650$ is slight as shown in Figure 4 and we therefore choose to convexify the budget constraint by taking its convex hull.

Our calculations are provided for 2006. We have used the CPS Labor Extracts, restricted to singles without children, to obtain the distribution of individual shown in Figure 5. In our computations, we do not smooth the distribution but use the actual individual data. Because the distribution is truncated in the CPS Labor Extracts, with a maximum of $\$ 150.000$ per year, we have completed it with a Pareto distribution. Because Saez (2001) has shown that US top incomes follow a Pareto distribution with parameter 2 , the underlying wages distribution follows a Pareto distribution with parameter 2 . Computationally, we adapt the procedure described in Subsection 3.1 to the utility 

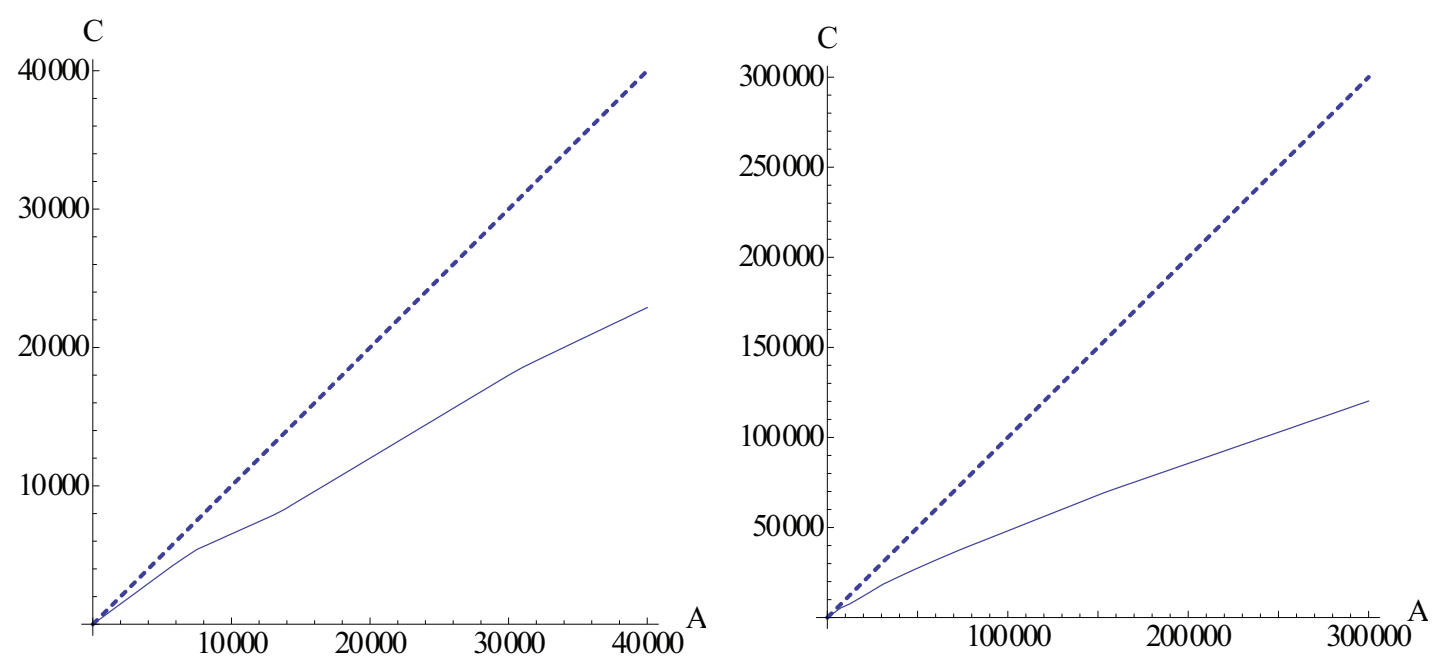

Figure 4: Nonlinear Budget Constraint in the US

function (22) and the distribution of wages in the US.

We study the average marginal deadweight loss of an increase in $t$ by 2.305 percentage points. That is $t$ is increased by $10 \%$. The results are shown in Table 1 . They contrast the results obtained using the correct procedure which does not rely on any linearization with those obtained when linearizing along segments of the US tax schedule. Rather than providing values for every possible linearization, from $\theta_{1}$ to $\theta_{14}$, we report results for linearizations along the first segment, the last segment and the segment along which the median individual optimizes. It appears that the linearization procedure usually leads to significant errors for both the marginal deadweight loss and the marginal tax revenue.

For $\beta=0.4$, the tax increase described above yields an additional tax revenue of $\$ 767.7$ per capita. The deadweight loss increases by $\$ 329.1$ per capita. Therefore, for any additional collected dollar, there is an extra loss of $\$ 0.442$.

Our results can be compared with those obtained by Feldstein (1999) who uses a linearization procedure and a value of $\beta$ equal to 1.04. His calculations incorporate the income tax rates and rules as of 1994. He finds that the incremental deadweight loss per dollar of additional revenue is about $\$ 2.06$. With the procedure described above and with the same value of $\beta$ as Feldstein, we find that the incremental deadweight loss is quite large but only of about $\$ 1$ in 2006 . 


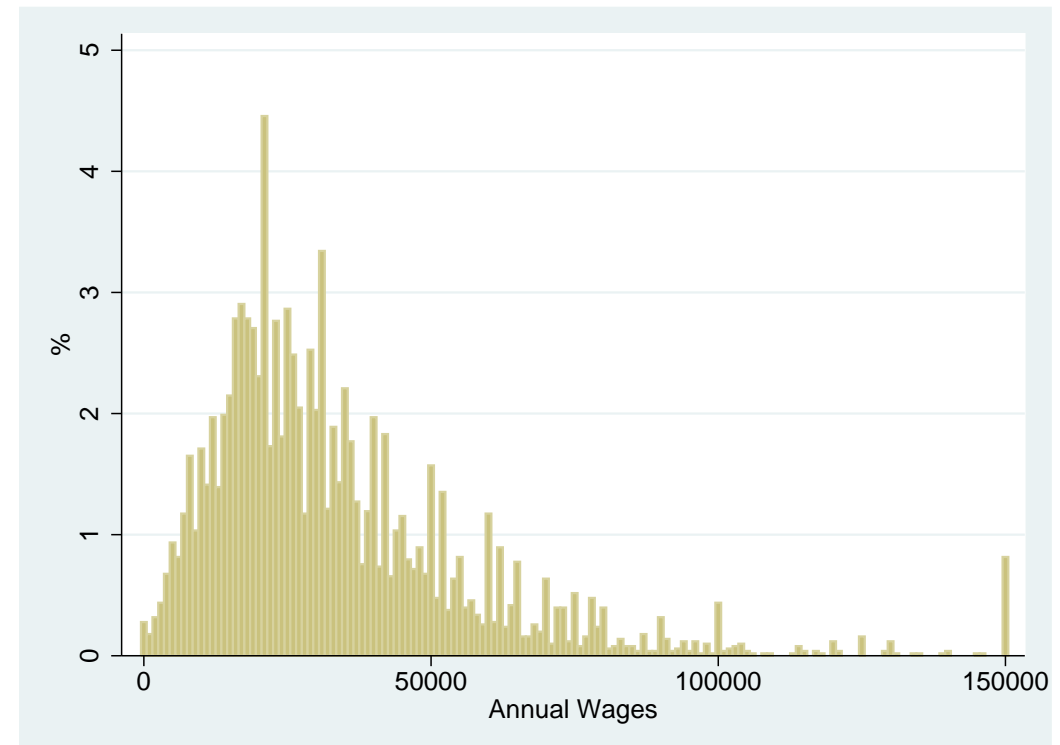

Figure 5: Distribution of Wages in 2006 in the US (from CPS Labor Extracts, for singles without children)

\begin{tabular}{|c|c|c|c|c|}
\hline Linearization & Variations (Per Capita) & $\beta=0.2$ & $\beta=0.4$ & $\beta=1.04$ \\
\hline \hline \multirow{2}{*}{ None } & Marginal Deadweight Loss & $\$ 194.5$ & $\$ 329.1$ & $\$ 537.1$ \\
& Marginal Tax Revenue & $\$ 830.1$ & $\$ 767.7$ & $\$ 539.3$ \\
& Ratio & $23.5 \%$ & $44.2 \%$ & $99.6 \%$ \\
\hline \hline \multirow{2}{*}{$\theta_{1}=0.736$} & Marginal Deadweight Loss & $\$ 59.7$ & $\$ 112.3$ & $\$ 239.9$ \\
& Marginal Tax Revenue & $\$ 779.8$ & $\$ 684.4$ & $\$ 433.6$ \\
& Ratio & $7.7 \%$ & $16.4 \%$ & $55.3 \%$ \\
\hline \multirow{2}{*}{$\theta_{6}=0.5995$} & Marginal Deadweight Loss & $\$ 106.7$ & $\$ 192.6$ & $\$ 360.9$ \\
& Marginal Tax Revenue & $\$ 737.0$ & $\$ 609.9$ & $\$ 311.8$ \\
& Ratio & $14.5 \%$ & $31.6 \%$ & $115.8 \%$ \\
\hline \multirow{2}{*}{$\theta_{14}=0.3265$} & Marginal Deadweight Loss & $\$ 291.7$ & $\$ 466.4$ & $\$ 592.4$ \\
& Marginal Tax Revenue & $\$ 607.2$ & $\$ 405.6$ & $\$ 73.4$ \\
& Ratio & $48.0 \%$ & $115.0 \%$ & $807.1 \%$ \\
\hline
\end{tabular}

Table 1: Marginal Deadweight Loss and Marginal Tax Revenue 


\section{Conclusion}

Actual tax systems are usually such that the marginal tax changes with the income level, implying that the budget constraints that individuals face are nonlinear. It is of interest to calculate the marginal deadweight loss of changes in a nonlinear income tax. A nonlinear income tax can be varied in many different ways. Break points can be changed, the intercept can be changed and the slope can be changed. Moreover, the slope can be changed in different ways. We do not cover all these different possibilities to vary a nonlinear tax. We focus on a particular kind of change in the slope, namely a change in the slope such that the marginal tax changes with the same number of percentage points at all income levels. Such a change can represent, for example, a change in the pay roll tax, the value added tax or a proportional state income tax. A common procedure to calculate the marginal deadweight loss of a change as described above has been to linearize the budget constraint at some point and then calculate the marginal deadweight loss for a variation in the linearized budget constraint. As shown in the article, such a procedure does not give the correct value of the marginal deadweight loss.

In this article, we first derive the correct way to calculate the marginal deadweight loss when the budget constraint is smooth and convex. It is well known that the size of the deadweight loss depends on the curvature of the indifference curves, with more curved indifference curves yielding smaller substitution effects and lower marginal deadweight losses. We show that the curvature of the budget constraint is equally important for the size of the marginal deadweight loss. In fact, the curvature of the budget constraint enters the expression for the marginal deadweight loss in exactly the same way as the curvature of the indifference curve.

We next show how to calculate the marginal deadweight loss when the tax system generates a piecewise linear budget constraint. It is equally true in this case as for the case with a smooth budget constraint that the curvature of the budget constraint is of the same importance for the marginal deadweight loss as the curvature of the indifference curve. However, the impact of the curvature of the budget constraint to diminish the deadweight loss is now concentrated to the kink points. For individuals located at a kink point, there is no marginal deadweight loss, for them the increase in the marginal tax is just like a lump-sum tax.

We also perform numerical calculations where we calculate the true marginal deadweight loss and compare this with computations obtained by linearizing the budget constraint and performing the marginal deadweight calculations on the linearized bud- 
get constraint. Depending on where the linearization is performed the linearization procedure will either under- or overpredict the true value of the marginal deadweight loss.

\section{References}

Blundell, R., And H. Hoynes (2004): Seeking a Premier Economy: The Economic Effects of British Economic Reforms, 1980-2000chap. Has In-Work Benefit Reform Helped the Labor Market?, pp. 411-460. NBER.

Burtless, G., And R. Moffitt (1984): Retirement and Economic Behaviorchap. The Effect of Social Security Benefits on the Labor Supply of the Aged, pp. 135-174. Brookings Institution.

Chapman, B., And A. Leigh (2009): "Do Very High Tax Rates Induce Bunching? Implications for the Design of Income-Contingent Loan Schemes," Economic Record, $85,276-289$.

Chetty, R. (2009): "Bounds on Elasticities with Optimization Frictions: A Synthesis of Micro and Macro Evidence on Labor Supply," NBER Working Paper 15616.

Dupuit, J. (1844): "De la mesure de l'utilite des travaux publics," Annales des Ponts et Chausses, 2, 332-375.

Feldstein, M. (1995): "Behavioral Responses to Tax Rates: Evidence from TRA86," American Economic Review, 85, 170-174.

- (1999): "Tax Avoidance and the Deadweight Loss of the Income Tax," Review of Economics and Statistics, 81, 674-680.

FriedBerG, L. (2000): "The Labor Supply Effects of the Social Security Earnings Test," Review of Economics and Statistics, 82, 48-63.

Gruber, J., And E. SAez (2002): "The Elasticity of Taxable Income: Evidence and Implications," Journal of Public Economics, 84, 1-32.

Harberger, A. (1962): "The incidence of the corporation income tax," Journal of Political Economy, 70, 215-240.

(1964): “The Measurement of Waste," American Economics Review, 54, 58-76. 
Kopczuk, W. (2005): "Tax bases, tax rates and the elasticity of reported income," Journal of Public Economics, 89, 2093-2119.

SAez, E. (2001): "Using Elasticities to Derive Optimal Income Tax Rates," Review of Economic Studies, 68, 205-229.

(2010): "Do Taxpayers Bunch at Kink Points," American Economic Journal: Economic Policy, p. forthcoming.

Saez, E., J. B. Slemrod, and S. H. Giertz (2009): "The Elasticity of Taxable Income with Respect to Marginal Tax Rates: A Critical Review," NBER Working Paper 15012. 
WORKING PAPERS*

Editor: Nils Gottfries

2008:11 Ranjula Bali Swain and Fan Yang Wallentin, Economic or Non-Economic Factors - What Empowers Women?. 34pp.

2008:12 Matz Dahlberg, Heléne Lundqvist and Eva Mörk, Intergovernmental Grants and Bureaucratic Power. 34pp.

2008:13 Matz Dahlberg, Kajsa Johansson and Eva Mörk, On mandatory activation of welfare receivers. 39pp.

2008:14 Magnus Gustavsson, A Longitudinal Analysis of Within-Education-Group Earnings Inequality. 26pp.

2008:15 Henrique S. Basso, Delegation, Time Inconsistency and Sustainable Equilibrium. 24pp.

2008:16 Sören Blomquist and Håkan Selin, Hourly Wage Rate and Taxable Labor Income Responsiveness to Changes in Marginal Tax Rates. 31 pp.

2008:17 Jie Chen and Aiyong Zhu, The relationship between housing investment and economic growth in China : A panel analysis using quarterly provincial data. 26pp.

2009:1 Per Engström, Patrik Hesselius and Bertil Holmlund, Vacancy Referrals, Job Search, and the Duration of Unemployment: A Randomized Experiment. $25 \mathrm{pp}$.

2009:2 Chuan-Zhong Li and Gunnar Isacsson, Valuing urban accessibility and air quality in Sweden: A regional welfare analysis. 24pp.

2009:3 Luca Micheletto, Optimal nonlinear redistributive taxation and public good provision in an economy with Veblen effects. $26 \mathrm{pp}$.

2009:4 Håkan Selin, The Rise in Female Employment and the Role of Tax Incentives. An Empirical Analysis of the Swedish Individual Tax Reform of $1971.38 \mathrm{pp}$.

2009:5 Lars M. Johansson and Jan Pettersson, Tied Aid, Trade-Facilitating Aid or Trade-Diverting Aid? 47pp.

2009:6 Håkan Selin, Marginal tax rates and tax-favoured pension savings of the selfemployed Evidence from Sweden. 32pp.

2009:7 Tobias Lindhe and Jan Södersten, Dividend taxation, share repurchases and the equity trap. $27 \mathrm{pp}$.

\footnotetext{
* A list of papers in this series from earlier years will be sent on request by the department.
} 
2009:8 Che-Yuan Liang, Nonparametric Structural Estimation of Labor Supply in the Presence of Censoring. 48pp.

2009:9 Bertil Holmlund, Incentives in Business and Academia. 12pp.

2009:10 Jakob Winstrand, The Effects of a Refinery on Property Values - The Case of Sweden. 27pp.

2009:11 Ranjula Bali Swain and Adel Varghese, The Impact of Skill Development and Human Capital Training on Self Help Groups. 28pp.

2009:12 Mikael Elinder. Correcting Mistakes: Cognitive Dissonance and Political Attitudes in Sweden and the United States. $25 \mathrm{pp}$.

2009:13 Sören Blomquist, Vidar Christiansen and Luca Micheletto: Public Provision of Private Goods and Nondistortionary Marginal Tax Rates: Some further Results. 41pp.

2009:14 Mattias Nordin, The effect of information on voting behavior. 34pp.

2009:15 Anders Klevmarken, Olle Grünewald and Henrik Allansson, A new consumer price index that incorporates housing. $27 \mathrm{pp}$.

2009:16 Heléne L. Nilsson, How Local are Local Governments? Heterogeneous Effects of Intergovernmental Grants. 41pp.

2009:17 Olof Åslund, Per-Anders Edin, Peter Fredriksson and Hans Grönqvist, Peers, neighborhoods and immigrant student achievement - evidence from a placement policy. $27 \mathrm{pp}$.

2009:18 Yunus Aksoy, Henrique S. Basso and Javier Coto-Martinez, Lending Relationships and Monetary Policy. 42 pp.

2009:19 Johan Söderberg, Non-uniform staggered prices and output persistence. $38 \mathrm{pp}$.

2010:1 Jonathan Gemus, College Achievement and Earnings. 43 pp.

2010:2 Susanne Ek and Bertil Holmlund, Family Job Search, Wage Bargaining, and Optimal Unemployment Insurance. 30 pp.

2010:3 Sören Blomquist and Laurent Simula, Marginal Deadweight Loss when the Income Tax is Nonlinear. $21 \mathrm{pp}$.

See also working papers published by the Office of Labour Market Policy Evaluation http://www.ifau.se/ 